\title{
Ethane and Propane Dehydrogenation over PtIr/Mg(Al)O
}

Jason Wu, Shaama Mallikarjun Sharada, Chris Ho, Andreas W. Hauser, Martin Head-Gordon Alexis T. Bell*

\author{
Department of Chemical and Biomolecular Engineering \\ University of California \\ Berkeley, CA 94720-1462
}

Submitted to Applied Catalysis A: General

*Corresponding author. E-mail address: bell@ @chem.berkeley.edu (A. T. Bell); Fax: +1 510642 4778.

\begin{abstract}
.
Increased demand for light alkenes has motivated research on the catalytic dehydrogenation of the light alkanes and on understanding the role of catalyst composition on
\end{abstract}


the activity, selectivity, and stability of Pt-based catalysts used for this purpose. The present study examines the structure and performance of Pt-Ir catalysts for ethane and propane dehydrogenation, and compares them with the performance of $\mathrm{Pt}$ and $\mathrm{Pt}-\mathrm{Sn}$ catalysts. Nanoparticles of Pt, PtSn, and PtIr were prepared in a colloidal suspension and then dispersed onto calcined hydrotalcite $(\mathrm{Mg}(\mathrm{Al}) \mathrm{O})$. After characterization to confirm formation of a bimetallic

alloy, it was observed that at high conversions, $\mathrm{Pt}_{3} \mathrm{Ir} / \mathrm{Mg}(\mathrm{Al}) \mathrm{O}$ exhibited lower initial activity than $\mathrm{Pt}_{3} \mathrm{Sn} / \mathrm{Mg}(\mathrm{Al}) \mathrm{O}$ but greater stability to coke deposition. Intrinsic rate measurements at low feed residence time revealed the following trend in activity: $\mathrm{Pt}_{3} \mathrm{Sn}>\mathrm{Pt}_{3} \mathrm{Ir}>\mathrm{Pt}$. DFT calculations carried out on tetrahedral clusters $\left(\mathrm{Pt}_{4}, \mathrm{Pt}_{3} \mathrm{Ir}, \mathrm{Pt}_{3} \mathrm{Sn}\right)$ reveals that this trend in activity can be replicated and Ir is capable of alkane activation, a trait unique to this bimetallic system.

Keywords. Platinum, Iridium, Tin, Bimetallic alloy, Ethane Dehydrogenation, Propane Dehydrogenation, Catalyst Deactivation

\section{Introduction}

Ethylene and propylene are used extensively as building blocks to produce a wide array of products, including plastics, rubbers, fuel blending agents, and chemical intermediates [1-3]. The conventional methods for producing light alkenes include steam cracking and fluid catalytic cracking of naphtha or gas oil. A typical product distribution from high-severity naphtha cracking yields $35 \%$ selectivity to ethylene and $15 \%$ selectivity to propylene, with substantial quantities of 
methane and coke as byproducts [4]. The low selectivity towards light alkenes and the drive to find more economical feedstocks compared to petroleum, has motivated the petrochemical industry to consider catalytic dehydrogenation of light alkanes as an attractive alternative. With the recent boom in natural gas production, especially in the United States, ethane and propane have become readily available and, hence, attractive the starting materials for the production of ethylene and propylene. The hydrogen produced as the principal byproduct of light alkane thermal dehydrogenation is also desirable, since it can be used as a fuel to provide the energy needed for the endothermic dehydrogenation process and for heteroatom removal from petroleum.

The most active catalyst for alkane dehydrogenation is platinum, but in its pure form, it suffers from low olefin selectivity and rapid coke deposition, leading to catalyst deactivation [3, 5]. The addition of promoters, such as Sn, In, or Ga [6-12], has been found to be effective in increasing alkene selectivity and suppressing coke formation [6, 8, 13-17]. Both geometric and electronic effects of the promoters have been proposed to elucidate their roles in modifying the catalyst for the reaction [18-21]. Catalyst stability can be further enhanced by using a metal oxide support free of acid sites that can promote side reactions and additional coking [17, 22-24]. Calcined hydrotalcite, or $\mathrm{Mg}(\mathrm{Al}) \mathrm{O}$, has been shown to be an ideal support for this reaction. Moreover, the Al cations present at the surface of this support surface stabilize the dispersed metal nanoparticles against sintering [25].

While primary attention has been given to $\mathrm{Sn}$ as the promoting element, a recent computational study has found Ir to be an effective promoter for propane dehydrogenation, and shows that Pt-Ir bimetallic particles should exhibit higher activity and greater stability than pure Pt [26]. Previous experimental studies of bimetallic Pt-Ir catalysts as reforming catalysts have shown that such catalysts are more active and less prone to coke formation compared to pure Pt [27-31]. In contrast to other promoting elements, Ir is unique in that it is capable of alkane activation [29, 32-34]. It is also noted that promotion of Ir together with Sn has been shown to significantly improve propane dehydrogenation activity while suppressing hydrogenolysis and 
other side reactions $[35,36]$. Therefore, Pt-Ir catalysts represent an interesting system in which both metals are capable alkane activation, but in the absence of a promoter, suffer from low selectivity and stability.

The aim of the present work was to investigate the catalytic properties Pt-Ir catalysts for ethane and propane dehydrogenation, and to compare their performance with $\mathrm{Pt}$ and $\mathrm{Pt}-\mathrm{Sn}$ catalysts. Pt-Ir nanoparticles were prepared in colloidal suspension and then supported on calcined hydrotalcite $(\mathrm{Mg}(\mathrm{Al}) \mathrm{O})$ using procedures described in Ref. 6. This catalyst preparation procedure was employed in order to produce nanoparticles of nearly uniform particle size and composition. Density functional theory calculations of the energies and Gibbs free energies of ethane dehydrogenation were carried out using a $\mathrm{Pt}_{3} \mathrm{X}(\mathrm{X}=\mathrm{Sn}$, Ir $)$ cluster to develop an understanding of the roles of Sn and Ir in enhancing catalyst activity for alkane dehydrogenation.

\section{Experimental}

\subsection{Synthesis of platinum, platinum-iridium, and platinum-tin nanoparticles}

Platinum nanoparticles were synthesized by reduction of a platinum acetylacetonate $\left(\mathrm{Pt}(\mathrm{acac})_{2}, 97 \%\right.$, Aldrich) dissolved in octyl ether (OE, 99\%, Aldrich) by 1,2-hexadecanediol (HDD, 90\%, Aldrich) in the presence of oleylamine (OAm, 70\%, Aldrich) and oleic acid (OA, 99\%, Aldrich) [37]. In a typical procedure, all of the components were added to a $25 \mathrm{ml}$ threenecked flask and the resulting solution was heated to $563 \mathrm{~K}$ at a rate of $2 \mathrm{~K} / \mathrm{min}$ and maintained at this temperature for 30 min before cooling down to room temperature. To produce Pt-Ir or PtSn bimetallic particles, iridium acetylacetonate $\left(\operatorname{Ir}(\mathrm{acac})_{3}, 97 \%\right.$, Aldrich) or tin acetylacetonate $\left(\mathrm{Sn}(\mathrm{acac})_{2}, 99.9 \%\right.$, Aldrich), respectively, was added together with $\mathrm{Pt}(\mathrm{acac})_{2}$ at the start of the synthesis in the appropriate ratio. Further details of the synthesis can be found in Table S1 of the Supporting Information. All the experiments were conducted under Ar using a standard Schlenk line. After the solution had cooled to room temperature, a large amount of anhydrous ethanol was added in order to aid the separation of the Pt nanoparticles, which was achieved by centrifugation 
at $3000 \mathrm{rpm}$ for $5 \mathrm{~min}$. The solid material produced in this manner was dispersed in anhydrous toluene to form a stable colloidal suspension. Details concerning the preparation of all samples are listed in Table S1.

\subsection{Synthesis of Pt/Mg(Al)O, PtIr/Mg(Al)O, PtSn/Mg(Al)O}

Synthetic hydrotalcite $\left(\mathrm{Mg}_{6} \mathrm{Al}_{2}\left(\mathrm{CO}_{3}\right)_{3}(\mathrm{OH})_{6} \cdot 4 \mathrm{H}_{2} \mathrm{O}, 100 \%\right.$, Aldrich) was calcined in air at $823 \mathrm{~K}$ for $5 \mathrm{~h}$ at a rate of $5 \mathrm{~K} / \mathrm{min}$. In a typical procedure, an appropriate volume $(5 \mathrm{~mL})$ of the toluene suspension of $\mathrm{Pt}$ or $\mathrm{Pt}-\mathrm{X}(\mathrm{X}=\mathrm{Ir}, \mathrm{Sn})$ particles dispersed in toluene was added to a suspension of $0.2 \mathrm{~g} \mathrm{Mg}(\mathrm{Al}) \mathrm{O}$ in $10 \mathrm{~mL}$ anhydrous toluene. The mixture was stirred overnight before the resulting product was precipitated by adding three times the volume anhydrous ethanol and separated by centrifugation. The solid material was heated at $723 \mathrm{~K}$ for $1 \mathrm{~h}$ in air to remove the surface capping agents and then reduced in an atmosphere of $\mathrm{H}_{2}$ in $\mathrm{Ar}(10 \mathrm{vol} . \%)$ at $873 \mathrm{~K}$ for $1 \mathrm{~h}$.

\subsection{Catalyst Characterization}

X-ray powder diffraction (XRD) patterns were collected on a Bruker D8 Discover GADDS Powder XRD equipped with a $\mathrm{Cu} \mathrm{K}_{\alpha}$ source (wavelength of $1.5418 \AA$ ). XRD scans were recorded digitally with a step size of 0.02 and evaluated with profile fitting methods. Transmission electron microscopy (TEM) was carried out at the Electron Microscopy Laboratory of the University of California, Berkeley using a FEI Tecnai 12 transmission electron microscope. The samples were prepared by adding ethanol $(2 \mathrm{~mL})$ to the colloid $(1 \mathrm{~mL})$, and the mixture was centrifuged to separate the particles. The black precipitate was re-suspended in 2 $\mathrm{mL}$ of toluene, and $0.1 \mathrm{~mL}$ of this solution was further diluted with $2 \mathrm{~mL}$ of toluene; $10 \mu \mathrm{L}$ of the suspension was dropped onto a lacey carbon copper grid. For the supported catalysts, $10 \mathrm{mg}$ of the catalyst was ground in $5 \mathrm{~mL}$ of ethanol and $20 \mu \mathrm{L}$ of the suspension was dropped onto a lacey carbon copper grid.

The Pt, Ir, and Sn contents of the bulk catalysts were determined by inductively coupled plasma - optical emission spectrometry (ICP-OES) by Galbraith Laboratories, Knoxville, TN. 
Elemental maps were recorded with a custom-modified FEI Titan electron microscope equipped with a Bruker Nano EDS detector at the National Center for Electron Microscopy. Maps were recorded at $200 \mathrm{kV}$ at a beam current of $0.5 \mathrm{nA}$ in the STEM mode after selecting a region of the sample by using the HAADF image. All elemental maps used a pixel dwell time of $150 \mathrm{~ms}$ with averaging of at least 100 frames with drift compensation. Bruker ESPRIT software package was used to quantify the maps by fitting and subtracting the Bremsstrahlung background using regions without peaks. After this step, the Pt L $\alpha$ emission peak at $9.439 \mathrm{keV}$ and the Ir L $\alpha$ peak at $9.175 \mathrm{keV}$ were integrated and converted to atomic compositions by using Cliff-Lorimer factors.

\subsection{Catalyst Testing}

Ethane and propane dehydrogenation was carried out in a fixed-bed, quartz reactor $(7 \mathrm{~mm}$ internal diameter). In a standard procedure, the catalyst materials were pressed, crushed, and sieved into small pellets (250-500 $\mathrm{m}$ in diameter). Prior to testing, the pelletized catalyst was heated at $723 \mathrm{~K}$ overnight in air to remove possible moisture from the support. The catalyst was heated to $873 \mathrm{~K}(15 \mathrm{~K} / \mathrm{min})$ in 1 atm $20 \% \mathrm{H}_{2}$ in $\mathrm{He}$ using a three-zone furnace and then maintained at $873 \mathrm{~K}$ for $1 \mathrm{~h}$ to fully reduce it. A feed containing alkane, hydrogen, and helium was used to determine the activity, selectivity, and stability of all $\mathrm{Pt} / \mathrm{Mg}(\mathrm{Al}) \mathrm{O}$ and $\mathrm{PtX} / \mathrm{Mg}(\mathrm{Al}) \mathrm{O}$ $(\mathrm{X}=\mathrm{Ir}, \mathrm{Sn})$ samples for ethane and propane dehydrogenation. The partial pressure of the alkane and the $\mathrm{H}_{2}$ /alkane ratio were fixed at 0.202 bar and 1 respectively. The reaction products were analyzed on-line by a gas chromatography - mass spectrometer (GC-MS, Varian, Model 320). A flame ionization detector (FID) was used to quantify the concentrations of all organic compounds eluting from the capillary column. Rates were normalized per gram Pt in the catalyst.

\subsection{DFT calculations}

The theoretical examination of ethane dehydrogenation on $\mathrm{Pt}$ and its alloys was

conducted along the lines of a previous computational study [21]. Tetrahedral arrangements of pure platinum, $\mathrm{Pt}_{4}$, and alloys, $\mathrm{Pt}_{3} \mathrm{X}(\mathrm{X}=\mathrm{Ir}, \mathrm{Sn})$ were chosen to represent the catalyst [21Error! 
Reference source not found.]. The minimum energy configurations for the $\mathrm{Pt}_{4}, \mathrm{Pt}_{3} \mathrm{Ir}_{\text {and }} \mathrm{Pt}_{3} \mathrm{Sn}$ correspond to a spin triplet, quartet and singlet, respectively.

All calculations were performed using the Q-Chem software package [38], with the $\omega B 97 X$ functional [39], and the triple-zeta valence basis set of Weigend and Ahlrichs [40], from which the f-functions were removed for performance reasons. The Stuttgart/Köln effective core potential $[41,42]$ was used for all metals. The transition states for the rate-limiting step, the first C-H bond breaking, were calculated using the freezing string method [43, 44].

Vibrational frequency calculations were performed on all structures, in order to verify the nature of stationary points as well as to calculate thermodynamic corrections. Vibrational analysis showed several low vibrational frequencies, corresponding to hindered or rocking modes of ethane relative to the metal cluster. The most commonly employed approximation of a rigid rotor-harmonic oscillator (RRHO) can yield erroneous thermodynamic corrections for lowlying frequencies. Therefore, the quasi-harmonic interpolation approach proposed by Grimme $[45,46]$ was used to calculate intrinsic free energies of activation of the $\mathrm{C}-\mathrm{H}$ bond. Theoretical free energies and reaction rates were then contrasted with experimental results in order to explain the differences in activity of various Pt alloys.

\section{Results and Discussion}

Figures $1 \mathrm{a}$ and $1 \mathrm{~b}$ show TEM images of the as-prepared $\mathrm{Pt}_{3} \mathrm{Ir}$ nanoparticles and the particle size distribution, respectively, with average particle size of $3.3 \mathrm{~nm}$. Upon calcination of the commercially available synthetic hydrotalcite material, calcined hydrotalcite, or $\mathrm{Mg}(\mathrm{Al}) \mathrm{O}$, is obtained as shown in Fig. 1c. The final $\mathrm{Pt}_{3} \mathrm{Ir} / \mathrm{Mg}(\mathrm{Al}) \mathrm{O}$ catalyst is obtained after deposition of the nanoparticles onto the support followed by calcination in order to remove the capping agents. The resulting TEM image (Fig. 1d) demonstrates that no change in particle size occurred upon dispersion of the nanoparticles onto the support. Table 1 presents a summary of the properties for the catalysts examined for ethane and propane dehydrogenation. A fair comparison of rates can be made due to the narrow range of particle sizes considered, resulting in similar dispersion 
values. Characterization of $\mathrm{Pt} / \mathrm{Mg}(\mathrm{Al}) \mathrm{O}$ and $\mathrm{Pt}_{3} \mathrm{Sn} / \mathrm{Mg}(\mathrm{Al}) \mathrm{O}$ by $\mathrm{TEM}$ and $\mathrm{XRD}$ are detailed in a previous publication [6].

XRD measurements of the support and catalysts are shown in Fig. 2. Hydrotalcite (black line) possess a brucite-like, layered, double hydroxide structure while the calcined hydrotalcite material (red line) resembles a cubic magnesium oxide $(\mathrm{MgO})$ structure with interstitial $\mathrm{Al}[11$, 47]. $\mathrm{Pt} / \mathrm{Mg}(\mathrm{Al}) \mathrm{O}$ (green line) and $\mathrm{Pt}_{3} \mathrm{Ir} / \mathrm{Mg}(\mathrm{Al}) \mathrm{O}$ (blue line) were prepared with $5 \%$ metal weight loading for XRD measurements in order to amplify the signal of the supported nanoparticles. Both catalysts showed distinct (111) diffraction peaks for fcc Pt or Ir metals, but due to the close proximity of the (111) peaks positions for Pt and Ir and the broad nature of the peaks, it is difficult to distinguish from XRD between a mixture of segregated Pt and Ir nanoparticles or PtIr bimetallic nanoparticles.

To confirm the microscopic composition of the individual nanoparticles, STEM-energy dispersive X-ray spectroscopy (STEM-EDS) was used to produce the elemental maps shown in Figs. 3a and 3b, which show the location of Pt and Ir, respectively. It can be seen qualitatively that there is strong overlap between the two maps, indicating that each particle contains both $\mathrm{Pt}$ and Ir and confirming the formation of a bimetallic Pt-Ir alloy. 10 elemental maps ( 300 nanoparticles) were collected in total for statistical purposes and bimetallic formation was observed in every case, with no indication of significant segregation of pure $\mathrm{Pt}$ or pure $\mathrm{Ir}$ nanoparticles. The quantification of the acquired count maps revealed an overall elemental composition of particles of $\mathrm{Ir} / \mathrm{Pt}=0.32$, in good agreement with the bulk ICP analysis. The distribution of particle compositions is shown in Figure S2.

The rate of ethane consumption and the selectivity to ethylene are shown in Fig. 4 for three different catalysts. Both $\mathrm{Pt}_{3} \mathrm{Ir} / \mathrm{Mg}(\mathrm{Al}) \mathrm{O}$ and $\mathrm{Pt}_{3} \mathrm{Sn} / \mathrm{Mg}(\mathrm{Al}) \mathrm{O}$ show significantly higher ethane conversion and stability compared to $\mathrm{Pt} / \mathrm{Mg}(\mathrm{Al}) \mathrm{O}$. Furthermore, the selectivity to ethylene increases to over $95 \%$ for the bimetallic catalysts as time on stream increases. This behavior is in agreement with previous studies that have observed increased activity, selectivity, and stability for Pt catalysts promoted with Sn, In, and Ga for ethane dehydrogenation [6-10]. 
$\mathrm{Pt}_{3} \mathrm{Ir} / \mathrm{Mg}(\mathrm{Al}) \mathrm{O}$ represents an interesting system since $\mathrm{Ir}$ atoms are active for alkane dehydrogenation, as well as Pt atoms, whereas $\mathrm{Sn}$ is incapable of alkane activation. Therefore, it is difficult to obtain a turnover frequency for Pt-Ir catalysts since it is not known experimentally how active $\mathrm{Pt}$ and Ir sites are relative to each other. We also note that a $\mathrm{Ir} / \mathrm{Mg}(\mathrm{Al}) \mathrm{O}$ catalyst prepared by the same procedure exhibited only $19 \%$ selectivity to ethylene under the same reaction conditions. Thus, Ir in bimetallic Pt-Ir nanoparticles behaves quite differently than in pure Ir nanoparticles.

Fig. 5 shows the percent deactivation in the first $10 \mathrm{~min}$ as a function of $\mathrm{M} / \mathrm{Pt}$ ratio $(\mathrm{M}=$ Ir, Sn). As more of the secondary metal is added to the catalyst, there is a significant decrease in deactivation, with Pt-Ir exhibiting slightly higher stability than Pt-Sn. Therefore, the accumulation of carbon decreases strongly with increased alloying with either Ir or Sn. This phenomenon has also been observed with other secondary metals, such as Ga and In [10, 11]. PtIr catalysts have also been long heralded as very stable reforming catalysts [29], and the same conclusion can be made for ethane dehydrogenation. It is also important to note that the percent loss in ethylene yield in the first 10 min shows identical trends as a function of M/Pt. For $\mathrm{Pt} / \mathrm{Mg}(\mathrm{Al}) \mathrm{O}$, there is a $54 \%$ loss in ethylene yield in the first 10 min while for $\mathrm{Pt}_{3} \mathrm{Ir} / \mathrm{Mg}(\mathrm{Al}) \mathrm{O}$ and $\mathrm{Pt}_{3} \mathrm{Sn} / \mathrm{Mg}(\mathrm{Al}) \mathrm{O}$ the losses are $24 \%$ and $12 \%$, respectively.

The activity and selectivity of each catalyst was probed for propane dehydrogenation, and the results are shown in Fig. 6. Both $\mathrm{Pt}_{3} \mathrm{Ir} / \mathrm{Mg}(\mathrm{Al}) \mathrm{O}$ and $\mathrm{Pt}_{3} \mathrm{Sn} / \mathrm{Mg}(\mathrm{Al}) \mathrm{O}$ showed increased propane conversion and higher propylene selectivity relative to $\mathrm{Pt} / \mathrm{Mg}(\mathrm{Al}) \mathrm{O}$. However, in contrast to what was observed for ethane dehydrogenation, the Sn-promoted catalyst exhibits $21 \%$ higher initial activity than the Ir-promoted catalyst. Fig. 7 shows the relative stability of both catalysts for propane dehydrogenation. Trends similar to those for ethane dehydrogenation (see Fig. 5) are observed. Therefore, we conclude that both $\mathrm{Pt}_{3} \mathrm{Ir} / \mathrm{Mg}(\mathrm{Al}) \mathrm{O}$ and $\mathrm{Pt}_{3} \mathrm{Sn} / \mathrm{Mg}(\mathrm{Al}) \mathrm{O}$ are significantly more active, selective, and stable than monometallic $\mathrm{Pt} / \mathrm{Mg}(\mathrm{Al}) \mathrm{O}$ for both ethane and propane dehydrogenation. Pt-Sn catalysts show higher initial activity while Pt-Ir catalysts exhibit slightly higher stability. 
To probe the intrinsic activity of these catalysts, the residence time was decreased in order to remove the effects of deactivation [6]. It has been observed that the initial deactivation of Pt or a promoted Pt catalyst for alkane dehydrogenation is very rapid, making it difficult to measure the true initial activity $[5,8]$. We have shown from previous isotopic labeling studies that coke originates primarily from readsorption of the formed alkene; therefore by measuring rates at low conversions, or low residence times, accurate comparisons of intrinsic activity of catalysts can be made with minimal influence of deactivation [6, 8]. Figs. $8 \mathrm{a}$ and $8 \mathrm{~b}$ show the rates of ethylene and propylene formation, respectively, at low-residence times. It is clear that both Pt-Ir and Pt-Sn catalysts are more active intrinsically for alkane dehydrogenation. From these data, we draw the conclusion that the activity for ethane and propane dehydrogenation decreases in the order $\mathrm{Pt}_{3} \mathrm{Sn}>\mathrm{Pt}_{3} \mathrm{Ir}>\mathrm{Pt}$.

The effect of hydrogen co-feed with ethane on ethylene formation is shown in Fig. 9. As the $\mathrm{H}_{2} / \mathrm{C}_{2} \mathrm{H}_{6}$ feed ratio increases, the rate of ethylene formation goes through a peak at $\mathrm{H}_{2} / \mathrm{C}_{2} \mathrm{H}_{6}=$ 1 , and then decreases. The observed effect of hydrogen has been observed previously for other Pt promoted with Ga or In [9-11]. It has been proposed that at low hydrogen partial pressures, the increase in adsorbed $\mathrm{H}$ atoms on the catalyst surface contributes to the removal of the second hydrogen from the adsorbed ethyl or propyl species, resulting in higher alkene formation rates [8]. Theoretical studies also suggest that the presence of adsorbed $\mathrm{H}$ atoms impedes the further dehydrogenation of adsorbed alkene molecules, a process leading to coke precursors, and facilitates alkene desorption and thereby the overall rate of alkane dehydrogenation [21]. We have observed these effects previously for Pt-Sn systems [6] but this trend can now be extended this effect to Pt-Ir.

Figure 8 shows the rate and selectivity for three cycles of ethane dehydrogenation over $\mathrm{Pt}_{3} \mathrm{Ir} / \mathrm{Mg}(\mathrm{Al}) \mathrm{O}$. After removal of accumulated carbon by oxidation and subsequent $\mathrm{H}_{2}$ reduction at $873 \mathrm{~K}$, the original performance of the catalyst was restored close to that seen in Cycle 1 . The particle size distributions in between cycles remained the same, eliminating the possibility of sintering during the oxidation and reduction steps. Because of the noble nature of Ir compared to 
other promoters such as Sn, In, or Ga, Pt-Ir catalysts may be a more durable catalyst in the presence of oxygen at the high temperatures needed to remove carbon species between cycles.

To gain an understanding of the cause in the observed activity with catalyst composition, a theoretical analysis of the elementary processes involved in ethane and propane dehydrogenation was carried out using tetrahedral metal clusters to represent the metal nanoparticles. The choice of this model is dictated by the fact that such clusters retain their tetrahedral architecture for all steps of the reaction sequence and have been shown previously to provide physically meaningful trends [21].

The transition states calculated for the first $\mathrm{C}-\mathrm{H}$ activation step for ethane on $\mathrm{Pt}_{3} \mathrm{Ir}$ are shown in Figure 11, along with the relevant bond distances. It is notable that the reaction can be catalyzed at both the $\mathrm{Pt}\left(\mathrm{Pt}_{3} \mathrm{Ir}\right)$ and $\mathrm{Ir}\left(\mathrm{IrPt}_{3}\right)$ centers, unlike $\mathrm{Pt}_{3} \mathrm{Sn}$ where dissociative adsorption of ethane does not occur on the $\mathrm{Sn}$ atom. The transition state geometry is similar to that previously determined for propane dehydrogenation on $\mathrm{Pt}$ alloy clusters $\left(\mathrm{Pt}_{4}\right.$ and $\left.\mathrm{Pt}_{3} \mathrm{X}\right)[21]$, as well as that for ethane dehydrogenation occurring on the (111) and (110) surfaces of bulk Pt [48]. Intrinsic enthalpies and free energies of activation for dissociative adsorption are reported in Table 2. Because the binding energy of ethane on $\operatorname{Pt}(111)$ and $\operatorname{Ir}(111)$ are within $0.1 \mathrm{kcal} / \mathrm{mol}$ [49], the intrinsic activation energy of the rate-determining step serves as an accurate basis for comparing the activities $\mathrm{Pt}$ and $\mathrm{Pt}_{3} \mathrm{Ir}$. The values of the activation barriers are lower than that reported for the $\mathrm{Pt}(110)$ surface $(40 \mathrm{~kJ} / \mathrm{mol})$ [48]. However, this may be a consequence of using a very small cluster to represent the $\mathrm{Pt}_{3} \mathrm{X}$ nanoparticles. The metals atoms are significantly undercoordinated in a 4-atom cluster, which may result in higher activity when compared to the true catalyst surface.

The trends in activation free energy predicted using theory are surprisingly close to those observed experimentally. Reaction rates and rate ratios relative to pure Pt were calculated, and reported in Table 2 . Since the activity for $\mathrm{Pt}_{3} \mathrm{Ir}$ varies widely depending on whether $\mathrm{Pt}$ or Ir is the 
active center, the Boltzmann averaged rates over both active sites is calculated prior to obtaining the rate ratio. As a result, the dissociative adsorption step at $\mathrm{Pt}_{3} \mathrm{Ir}$ is determined to be 4.6 times faster than at $\mathrm{Pt}_{4}$. The theoretical activity trend of $\mathrm{Pt}_{3} \mathrm{Sn}>\mathrm{Pt}_{3} \mathrm{Ir}>\mathrm{Pt}_{4}$ agrees qualitatively with that found experimentally. Concurrent work has shown that the trend in activity can be related to the HOMO-LUMO gap of the metal cluster [26]. The gap is smallest for $\mathrm{Pt}_{3} \mathrm{Sn}$ and largest for pure $\mathrm{Pt}$, which may be the cause of lower $\mathrm{C}-\mathrm{H}$ activation energy at the former. A detailed analysis of factors governing activity and selectivity in Pt alloys has been presented elsewhere [26].

\section{Conclusion}

Catalysts for ethane and propane dehydrogenation were prepared by ex-situ formation of Pt, Pt-Ir, and Pt-Sn nanoparticles in solution, and subsequent deposition onto calcined hydrotalcite. Characterization by XRD and STEM-EDS confirmed the presence of metallic nanoparticles with an fcc structure containing Pt and Ir in close association, indicating bimetallic alloy formation. $\mathrm{Pt}_{3} \mathrm{Ir} / \mathrm{Mg}(\mathrm{Al}) \mathrm{O}$ and $\mathrm{Pt}_{3} \mathrm{Sn} / \mathrm{Mg}(\mathrm{Al}) \mathrm{O}$ exhibited superior performance for both ethane and propane dehydrogenation compared to $\mathrm{Pt} / \mathrm{Mg}(\mathrm{Al}) \mathrm{O}$, with $\mathrm{PtIr} / \mathrm{Mg}(\mathrm{Al}) \mathrm{O}$ showing slightly higher stability than $\mathrm{PtSn} / \mathrm{Mg}(\mathrm{Al}) \mathrm{O}$. Low residence-time experiments revealed that PtIr catalysts are intrinsically more active than pure Pt catalyst and the trend in activity decreases in the order: $\mathrm{Pt}_{3} \mathrm{Sn}>\mathrm{Pt}_{3} \mathrm{Ir}>\mathrm{Pt}$. The rate of ethane dehydrogenation over $\mathrm{Pt}_{3} \mathrm{Ir} / \mathrm{Mg}(\mathrm{Al}) \mathrm{O}$ increases with the addition of $\mathrm{H}_{2}$ to the feed for feed ratios up to $\mathrm{H}_{2} / \mathrm{C}_{2} \mathrm{H}_{6}=1$ in a manner similar to that observed previously for other promoters. Theoretical analysis of ethane dehydrogenation on $\mathrm{Pt}_{4}$, $\mathrm{Pt}_{3} \mathrm{Ir}$, and $\mathrm{Pt}_{3} \mathrm{Sn}$ clusters yields the same trend observed experimentally, and reveals that both $\mathrm{Pt}$ and Ir atoms are capable of alkane activation, a characteristic not observed in the PtSn system.

\section{Acknowledgements}


This work was supported by Chevron Energy Technology Company. Work at the Molecular Foundry (Proposal \#3335) was supported by the Office of Science, Office of Basic Energy Sciences, of the U.S. Department of Energy under Contract No. DE-AC02-05CH11231.

\section{References}

1. F. Cavani, N. Ballarini, A. Cericola, Catal. Today 127 (2007) 113-131.

2. R.S. Vincent, R.P. Lindstedt, N.A. Malik, I.A.B. Reid, and B.E. Messenger, J. Catal. 260 (2008) 37-64.

3. J.J.H.B. Sattler, J. Ruiz-Martinez, E. Santillan-Jimenez, B.M. Weckhuysen, Chem. Rev. 114 (2014) 10613-10653.

4. K. Weissermel, H. Arpe, Industrial Organic Chemistry, 3rd ed., Wiley Inc., 2008, pp. 66.

5. D.E. Resasco, Dehydrogenation - Heterogeneous, in: I.T. Horváth (Ed.), Encyclopedia of Catalysis, Wiley, New York, 2003, pp. 49-79.

6. J. Wu, Z. Peng, A.T. Bell, J. Catal. 311 (2014) 161-168.

7. J. Wu, Z. Peng, P. Sun, A.T. Bell, Appl. Catal. A: Gen. 470 (2014) 161-168.

8. V. Galvita, G. Siddiqi, P. Sun, A.T. Bell, J. Catal. 271 (2010) 209-219.

9. G. Siddiqi, P. Sun, V. Galvita, A.T. Bell, J. Catal. 274 (2010) 200-206.

10. P. Sun, G. Siddiqi, M.F. Chi, A.T. Bell, J. Catal. 274 (2010) 192-199.

11. P. Sun, G. Siddiqi, W.C. Vining, M.F. Chi, A.T. Bell, J. Catal. 282 (2011) 165-174.

12. E.L. Jablonski, A.A. Castro, O.A. Scelza, and S.R. de Miguel, Appl. Catal. A: Gen. 183 (1999) 189-198.

13. R.D. Cortright, J.M. Hill, J.A. Dumesic, Catal. Today 55 (2000) 213-223.

14. A. Virnovskaia, E. Rytter, U. Olsbye, Ind. Eng. Chem. Res. 47 (2008) 7167-7177.

15. A.D. Ballarini, C.G. Ricci, M.S.R. de, O.A. Scelza, Catal. Today 133-135 (2008) 28-34.

16. L. Bednarova, C.E. Lyman, E. Rytter, A. Holmen, J. Catal. 211 (2002) 335-346.

17. J. Salmones, J.-A. Wang, J.A. Galicia, G. Aguilar-Rios, J. Mol. Catal. A: Chem. 184 (2002) 203-213.

18. R. Alcala, J.W. Shabaker, G.W. Huber, M.A. Sanchez-Castillo, J.A. Dumesic, J. Phys. Chem. B 109 (2005) 2074-2085.

19. J.Y. Shen, J.M. Hill, R.M. Watwe, B.E. Spiewak, J.A. Dumesic, J. Phys. Chem. B 103 (1999) 3923-3934.

20. R.M. Watwe, R.D. Cortright, M. Mavrikakis, J.K. Norskov, J.A. Dumesic, J. Chem. Phys. 114 (2001) 4663-4668.

21. A.W. Hauser, J. Gomes, M. Bajdich, M. Head-Gordon, A.T. Bell, Phys. Chem. Chem. Phys. 15 (2013) 20727-20734.

22. H. Armendariz, A. Guzman, J.A. Toledo, M.E. Llanos, A. Vazquez, G. Aguilar-Rios, Appl. Catal. A 211 (2001) 69-80.

23. A.D. Ballarini, S.A. Bocanegra, A.A. Castro, M.S.R. de, O.A. Scelza, Catal. Lett. 129 (2009) 293-302.

24. S.A. Bocanegra, A. Guerrero-Ruiz, M.S.R. de, O.A. Scelza, Appl. Catal. A: Gen. 277 (2004) 11-22. 
25. J.H. Kwak, J. Hu, D. Mei, C.-W. Yi, D.H. Kim, C.H.F. Peden, L.F. Allard, J. Szanyi, Science 325 (2009) 1670-1673.

26. A.W. Hauser, P.R. Horn, M. Head-Gordon, A.T. Bell, in preparation

27. J.C. Rasser, W.H. Beindorff, J.J.F. Scholten, J. Catal. 59 (1979) 211-222.

28. N. Macleod, J.R. Fryer, D. Stirling, G. Webb, Catal. Today 46 (1998) 37-54.

29. J.C. Rasser, Platinum-Iridium Reforming Catalysts, Delft University, Delft, Netherland, 1977.

30. J.H. Sinfelt, G.H. Via, J. Catal. 56 (1979) 1-11.

31. R. Rice, K. Lu, J. Catal. 77 (1982) 104-117.

32. J.L. Carter, J.A. Cusumano, J.H. Sinfelt, J. Catal. 20 (1971) 223-229.

33. J.R. Engstrom, D.W. Goodman, W.H. Weinberg, J. Am. Chem. Soc. 110 (1988) 83058319.

34. K. Foger, J.R. Anderson, J. Catal. 59 (1979) 325-339.

35. D.M. Somerville, J.R. Shapley, Catal. Lett. 52 (1998) 123-129.

36. M. Guidotti, V.D. Santo, A. Gallo, E. Gianotti, G. Peli, R. Psaro, L. Sordelli Catal. Lett. 112 (2006) 89-95.

37. F. Somodi, Z. Peng, A. Getsoian, A.T. Bell, J. Phys. Chem. C 115 (2011) 19084-19090.

38. Y. Shao et al. Mol. Phys. 113 (2015) 184-215.

39. J-D. Chai, M. Head-Gordon, J. Chem. Phys. 128 (2008) 084106.

40. F. Weigend, R. Ahlrichs, Phys. Chem. Chem. Phys. 7 (2005) 3297-3305.

41. D. Andrae, U. Haussermann, M. Dolg, H. Stoll, H. Preuss, Theor. Chem. Acta. 77 (1990), 123-141.

42. B. Metz, H. Stoll, M. Dolg, J. Chem. Phys. 113 (2000), 2563-2569.

43. A. Behn, P.M. Zimmerman, A.T. Bell, M. Head-Gordon, J. Chem. Phys. 135 (2011) 224108.

44. S.M. Sharada, P.M. Zimmerman, A.T. Bell, M. Head-Gordon, J. Chem. Theory. Comput. 8 (2012) 5166-5174.

45. S. Grimme, Chem. Eur. J. 18 (2012) 9955-9964.

46. Y-P, Li, J. Gomes, S.M. Sharada, A.T. Bell, M. Head-Gordon, J. Phys. Chem. C. 119 (2015) 1840-1850.

47. H.C. Liu, X.Y. Yang, G.P. Ran, E.Z. Min, J.K. Liu, P.L Ying, Q. Xin, C. Li, Chin. J. Chem. 17 (1999) 319-330.

48. A.T. Anghel, D.J. Wales, S.J. Jenkins, D.A. King, Chem. Phys. Lett. 413 (2005) 289-293.

49. A.V. Zeigarnik, R.E. Valdés-Pérez, O.N. Myatkovskaya, J. Phys. Chem. B 104 (2000) 10578-10587 

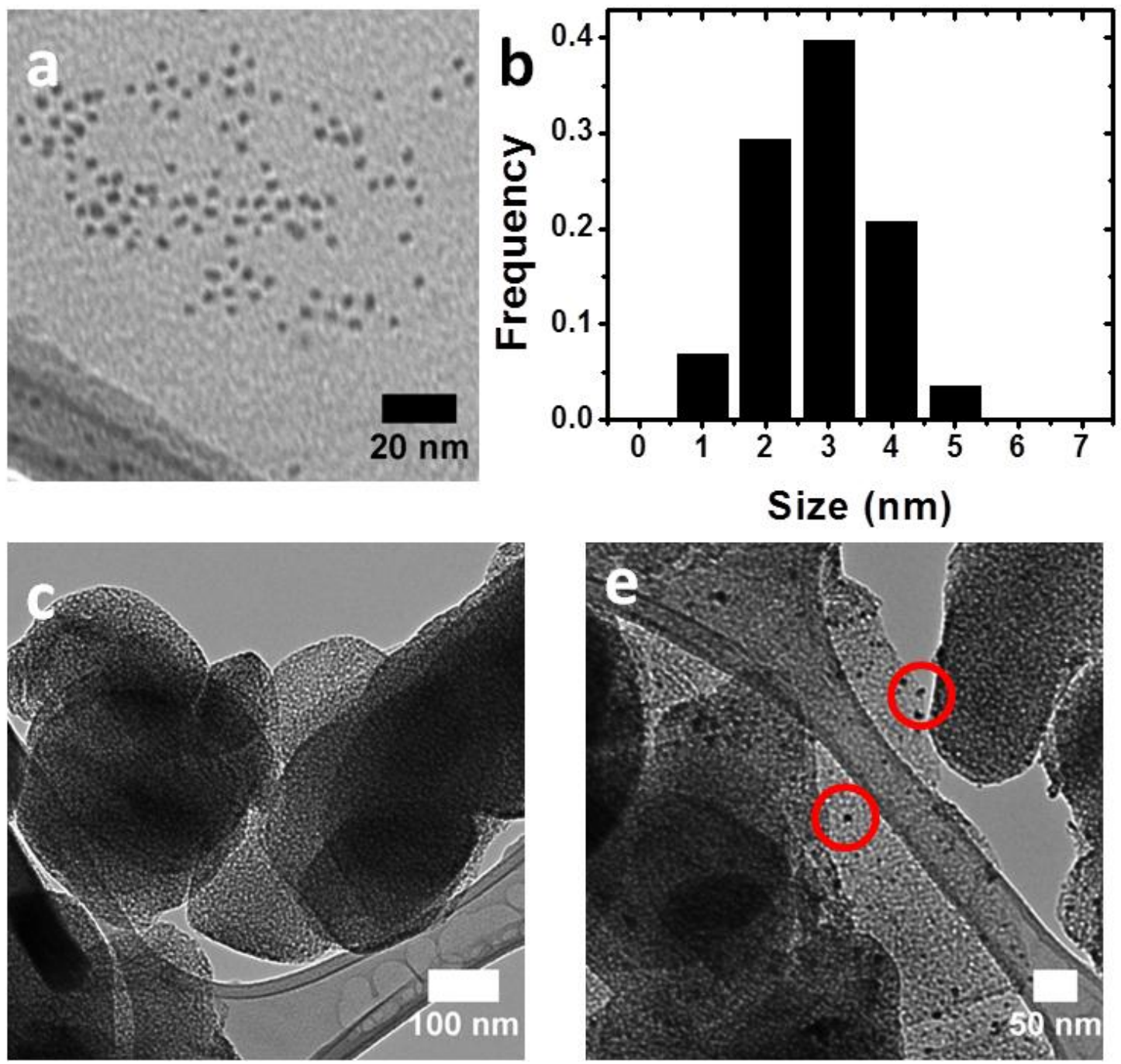

Fig. 1. a) $\mathrm{Pt}_{3} \mathrm{Ir}$ nanoparticles prepared ex-situ by colloidal method, b) Particle size distribution with $<\mathrm{d}>=3.3 \mathrm{~nm}$, c) Calcined hydrotalcite after calcination of synthetic hydrotalcite at $823 \mathrm{~K}$ for $5 \mathrm{~h}$, e) $\mathrm{Pt}_{3} \mathrm{Ir} / \mathrm{Mg}(\mathrm{Al}) \mathrm{O}$ catalysts after nanoparticle deposition onto calcined support. 


\begin{tabular}{c|c|c|c} 
Catalyst & Pt wt\% & M wt\% $(\mathbf{M}=\mathbf{I r}$ or Sn) & $<\mathbf{d}>(\mathbf{n m})$ \\
\hline $\mathrm{Pt} / \mathrm{Mg}(\mathrm{Al}) \mathrm{O}$ & 1.84 & 0 & 3.8 \\
$\mathrm{Pt}_{5} \mathrm{Ir} / \mathrm{Mg}(\mathrm{Al}) \mathrm{O}$ & 2.00 & 0.47 & 4.2 \\
$\mathrm{Pt}_{3} \mathrm{Ir} / \mathrm{Mg}(\mathrm{Al}) \mathrm{O}$ & 1.91 & 0.68 & 3.3 \\
$\mathrm{Pt}_{3} \mathrm{Sn} / \mathrm{Mg}(\mathrm{Al}) \mathrm{O}$ & 1.63 & 0.42 & 3.5
\end{tabular}

Table 1. Composition and particle size distribution determined by ICP-OES and TEM, respectively.

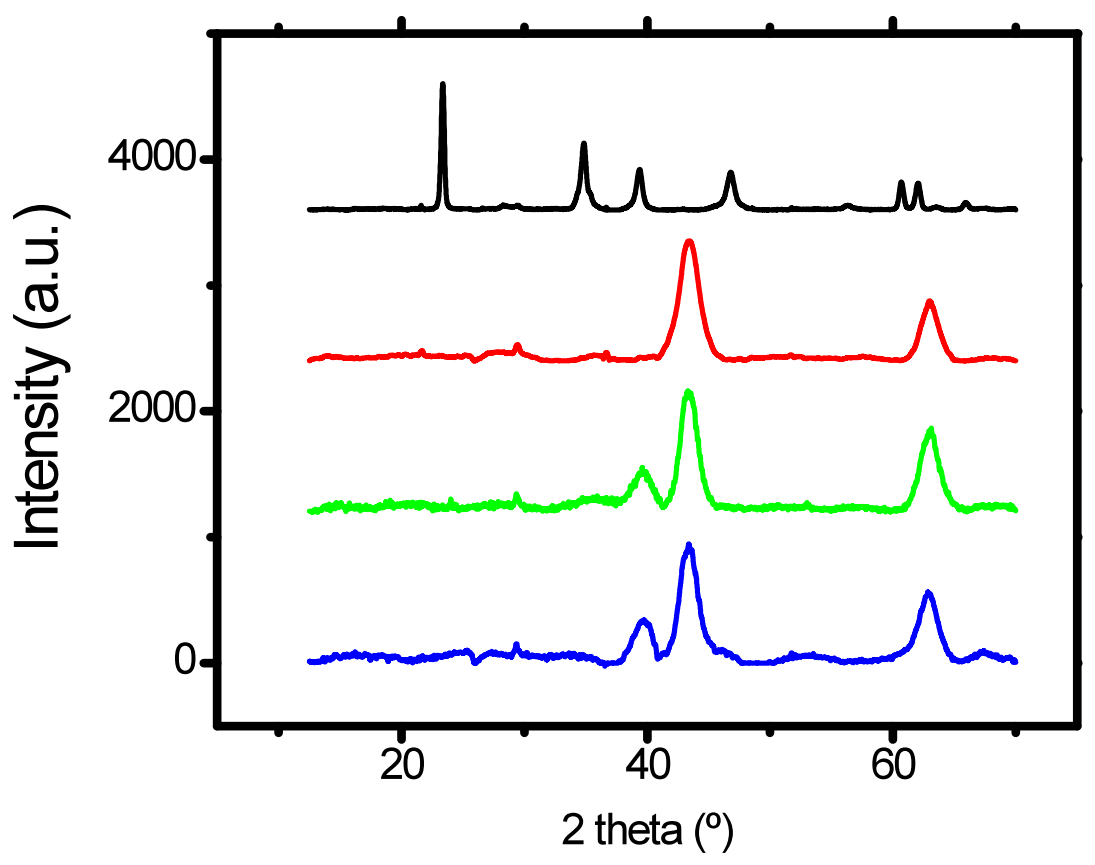

Fig. 2. XRD patterns for synthetic hydrotalcite (black), calcined hydrotalcite (red), $\mathrm{Pt} / \mathrm{Mg}(\mathrm{Al}) \mathrm{O}$ (green), and $\mathrm{Pt}_{3} \operatorname{Ir} / \mathrm{Mg}(\mathrm{Al}) \mathrm{O}$ (blue). 


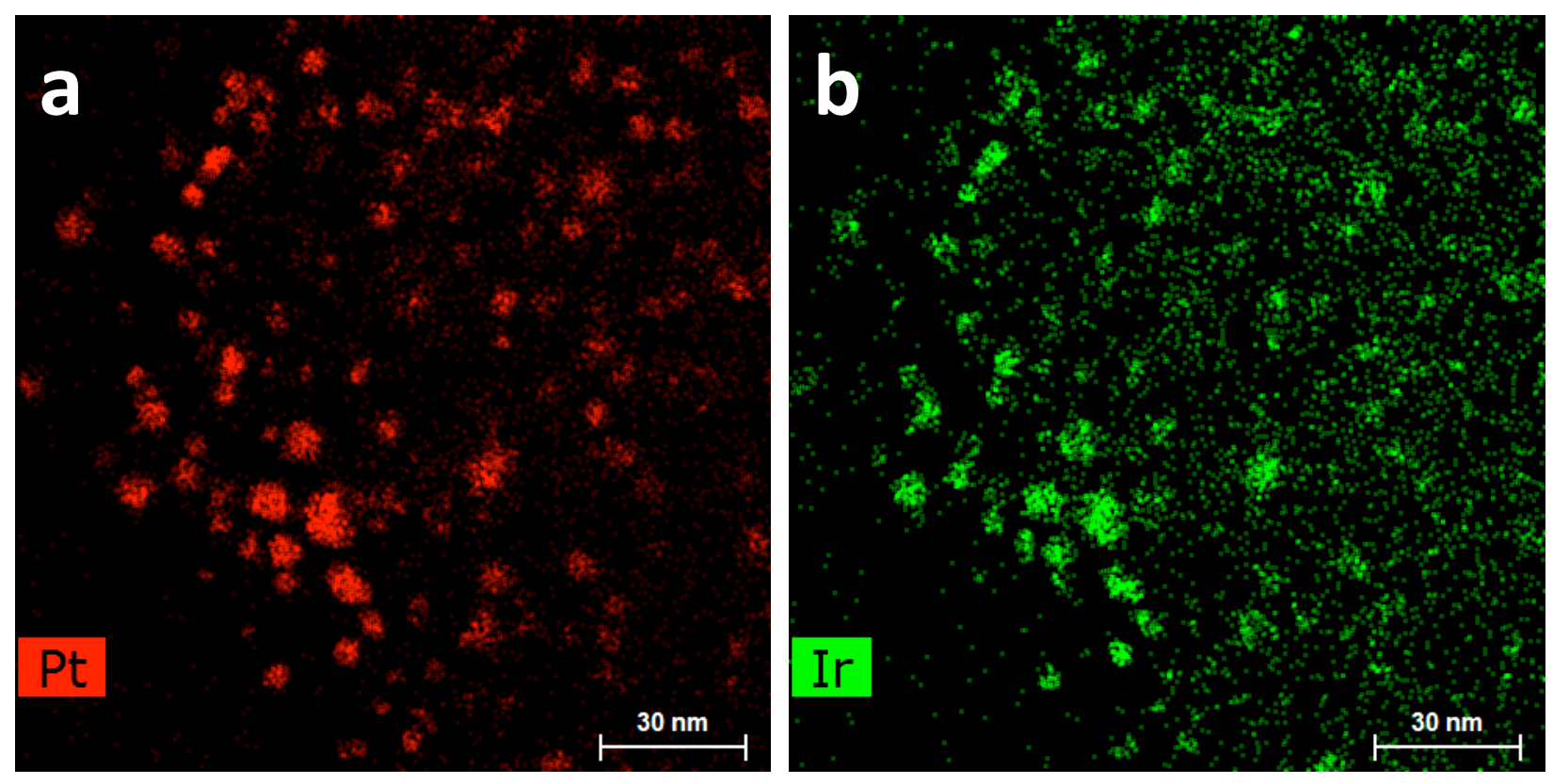

Fig. 3. Elemental mapping of $\mathrm{Pt}_{3} \mathrm{Ir} / \mathrm{Mg}(\mathrm{Al}) \mathrm{O}$ by STEM-EDS. 

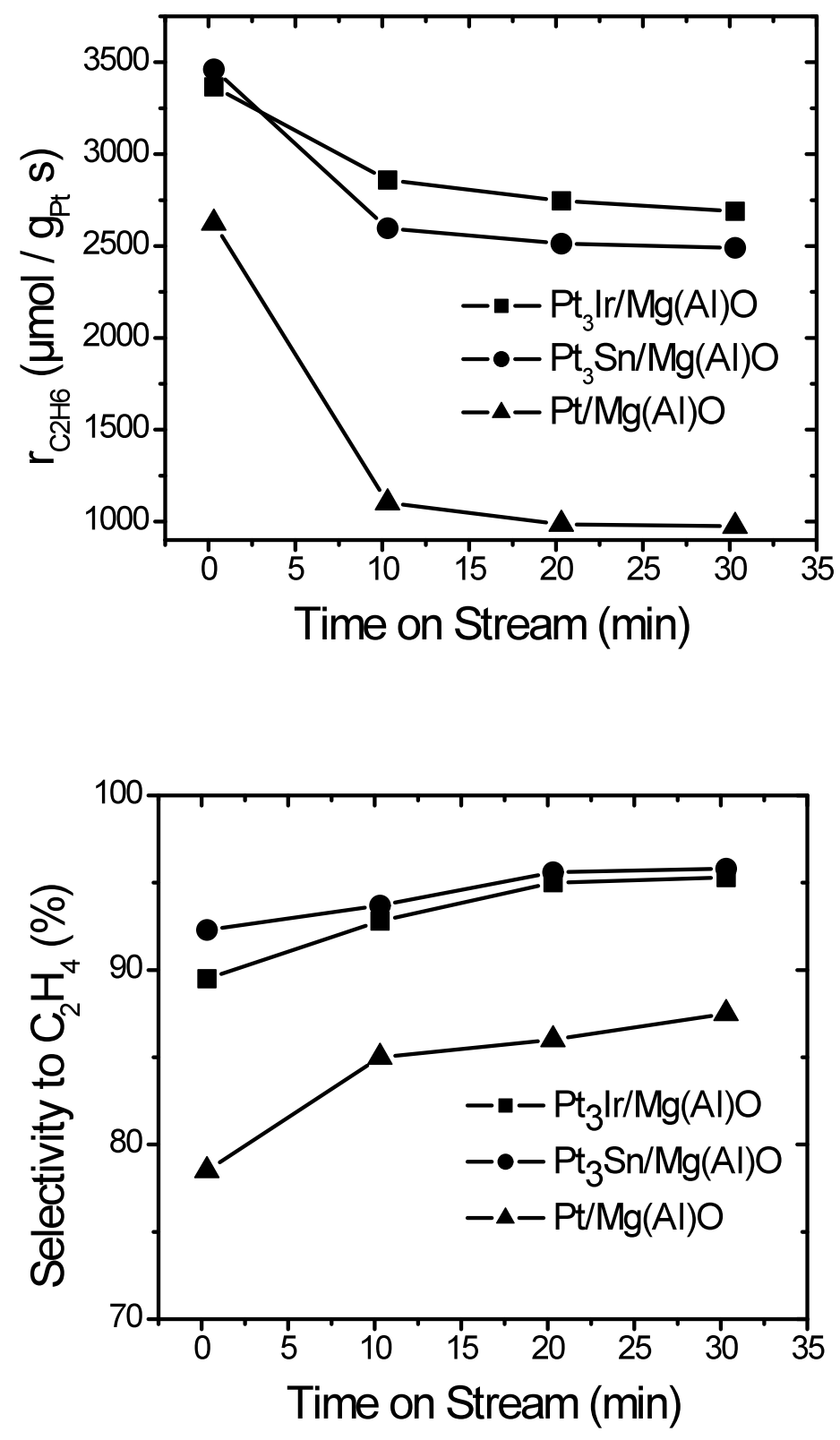

Fig. 4. The rate of ethane conversion and selectivity to ethylene as a function of time on stream for $\mathrm{Pt}_{3} \mathrm{Ir}, \mathrm{Pt}_{3} \mathrm{Sn}$, and $\mathrm{Pt}$ catalysts supported on calcined hydrotalcite. Reaction conditions: $873 \mathrm{~K}, \mathrm{~m}=25 \mathrm{mg}, \mathrm{F}=60 \mathrm{~mL} / \mathrm{min}, \mathrm{C}_{2} \mathrm{H}_{6}: 20 \%, \mathrm{H}_{2}: \mathrm{C}_{2} \mathrm{H}_{6}=1$ 


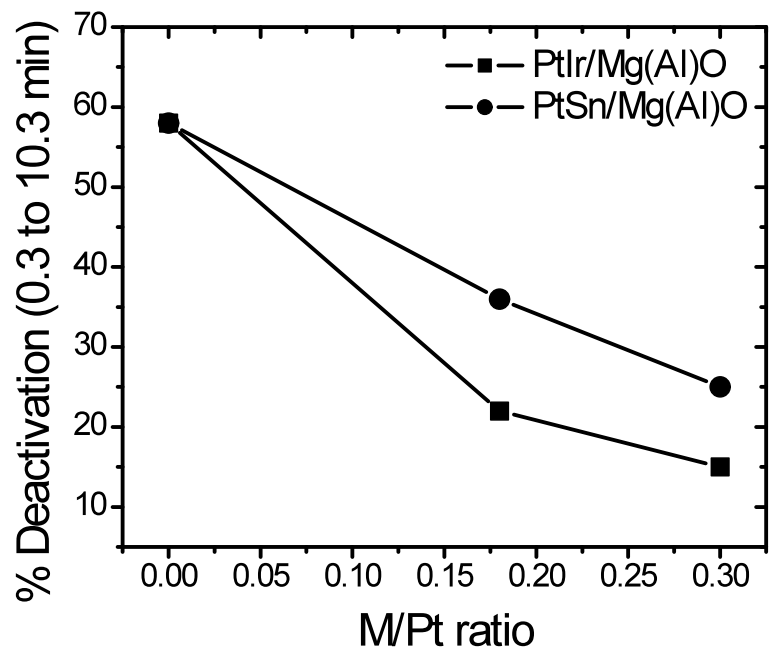

Fig. 5. Percent deactivation in the first 10 minutes of ethane dehydrogenation as a function of M/Pt ratio. Reaction conditions: $873 \mathrm{~K}, \mathrm{~m}=25 \mathrm{mg}, \mathrm{F}=60 \mathrm{~mL} / \mathrm{min}, \mathrm{C}_{2} \mathrm{H}_{6}$ : $20 \%, \mathrm{H}_{2}: \mathrm{C}_{2} \mathrm{H}_{6}=1$ 

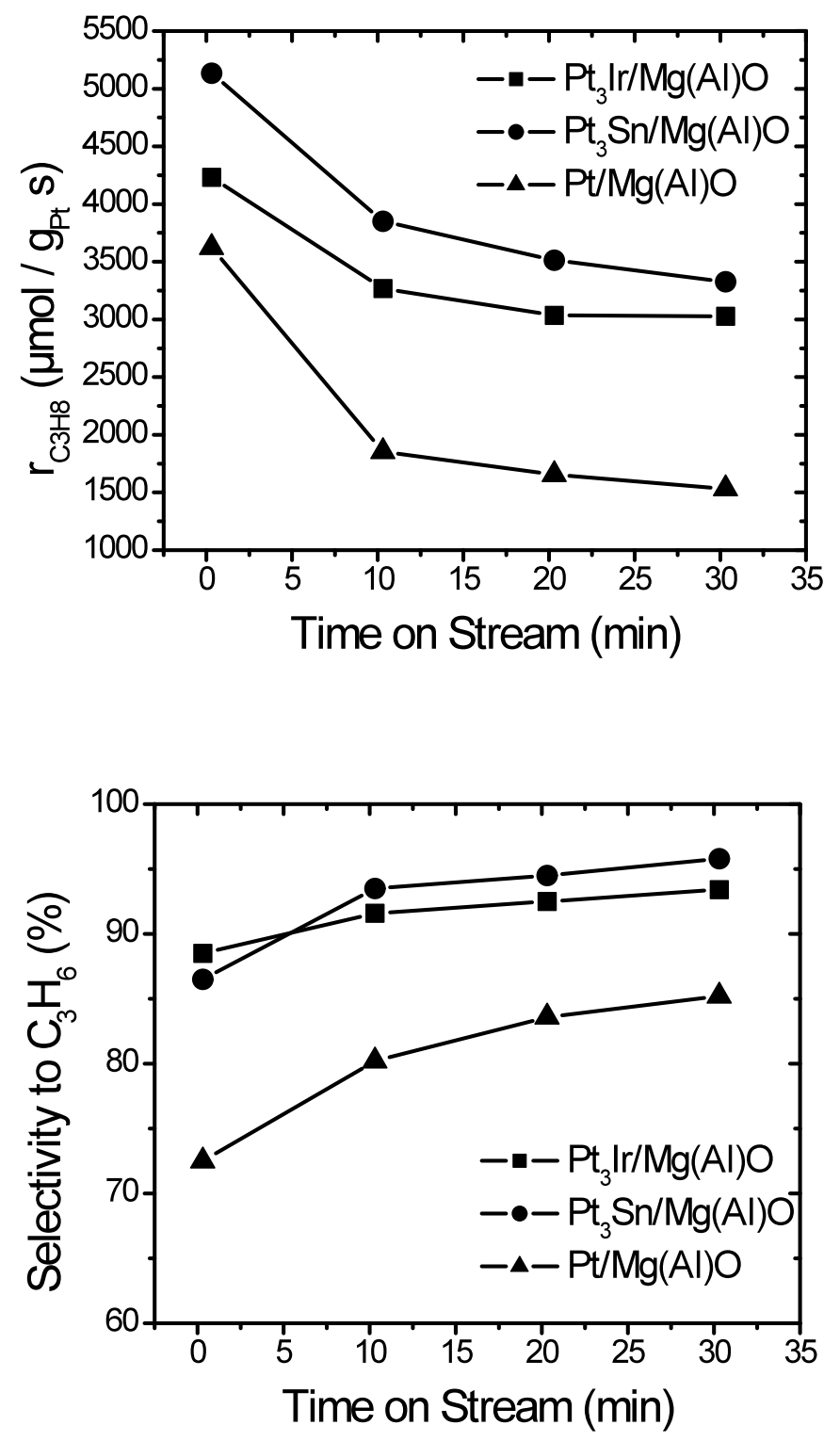

Fig. 6. The rate of propane conversion and selectivity to propylene as a function of time on stream for $\mathrm{Pt}_{3} \mathrm{Ir}, \mathrm{Pt}_{3} \mathrm{Sn}$, and $\mathrm{Pt}$ catalysts supported on calcined hydrotalcite. Reaction conditions: $873 \mathrm{~K}, \mathrm{~m}=25 \mathrm{mg}, \mathrm{F}=60 \mathrm{~mL} / \mathrm{min}, \mathrm{C}_{3} \mathrm{H}_{8}: 20 \%, \mathrm{H}_{2}: \mathrm{C}_{2} \mathrm{H}_{8}=1$ 


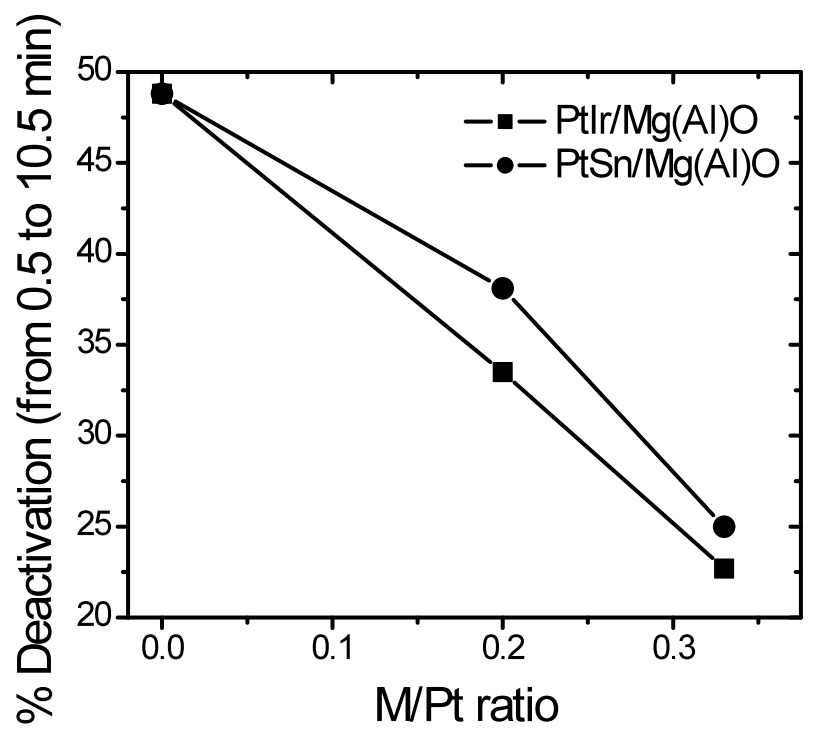

Fig. 7. Percent deactivation in the first 10 minutes of propane dehydrogenation as a function of M/Pt ratio. Reaction conditions: $873 \mathrm{~K}, \mathrm{~m}=25 \mathrm{mg}, \mathrm{F}=60 \mathrm{~mL} / \mathrm{min}, \mathrm{C}_{3} \mathrm{H}_{8}$ : $20 \%, \mathrm{H}_{2}: \mathrm{C}_{3} \mathrm{H}_{8}=1$ 

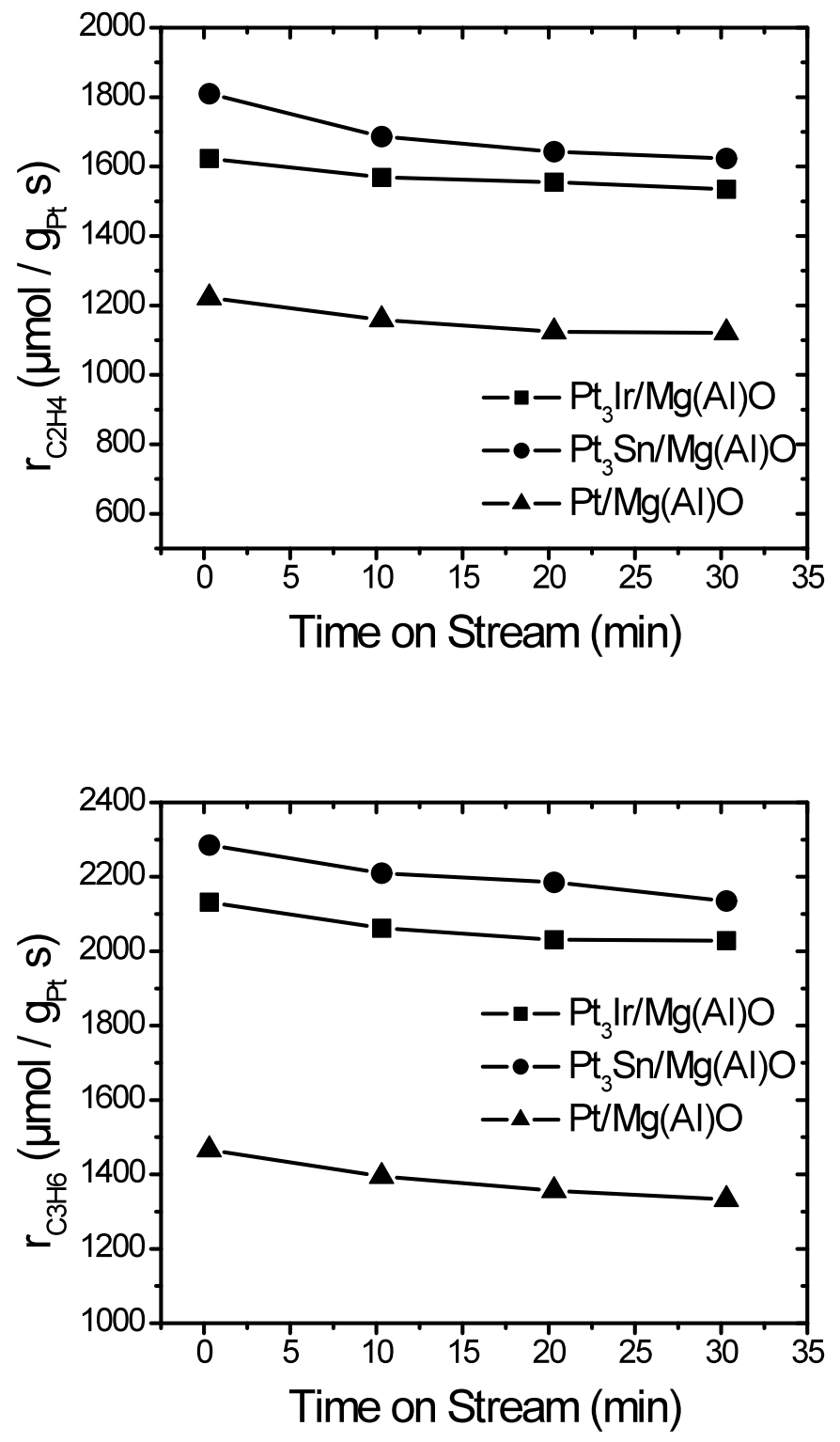

Fig. 8. Rate of ethylene and propylene production as a function of time on stream at lowresidence time. Reaction conditions: $873 \mathrm{~K}, \mathrm{~m}=5 \mathrm{mg}, \mathrm{F}=80 \mathrm{~mL} / \mathrm{min}, \mathrm{C}_{2} \mathrm{H}_{6}$ or $\mathrm{C}_{3} \mathrm{H}_{8}$ : $20 \%, \mathrm{H}_{2}:\left(\mathrm{C}_{2} \mathrm{H}_{6}\right.$ or $\left.\mathrm{C}_{3} \mathrm{H}_{8}\right)=1$ 


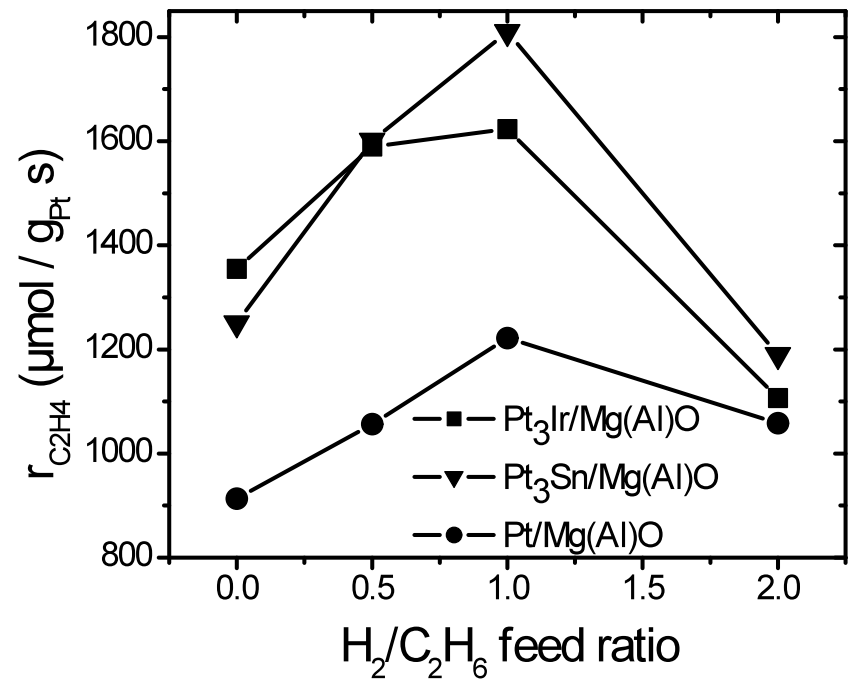

Fig. 9. Rate of ethylene production as a function of hydrogen to ethane feed ratio. Reaction conditions: $873 \mathrm{~K}, \mathrm{~m}=25 \mathrm{mg}, \mathrm{F}=60 \mathrm{~mL} / \mathrm{min}, \mathrm{C}_{2} \mathrm{H}_{6}: 20 \%$ 

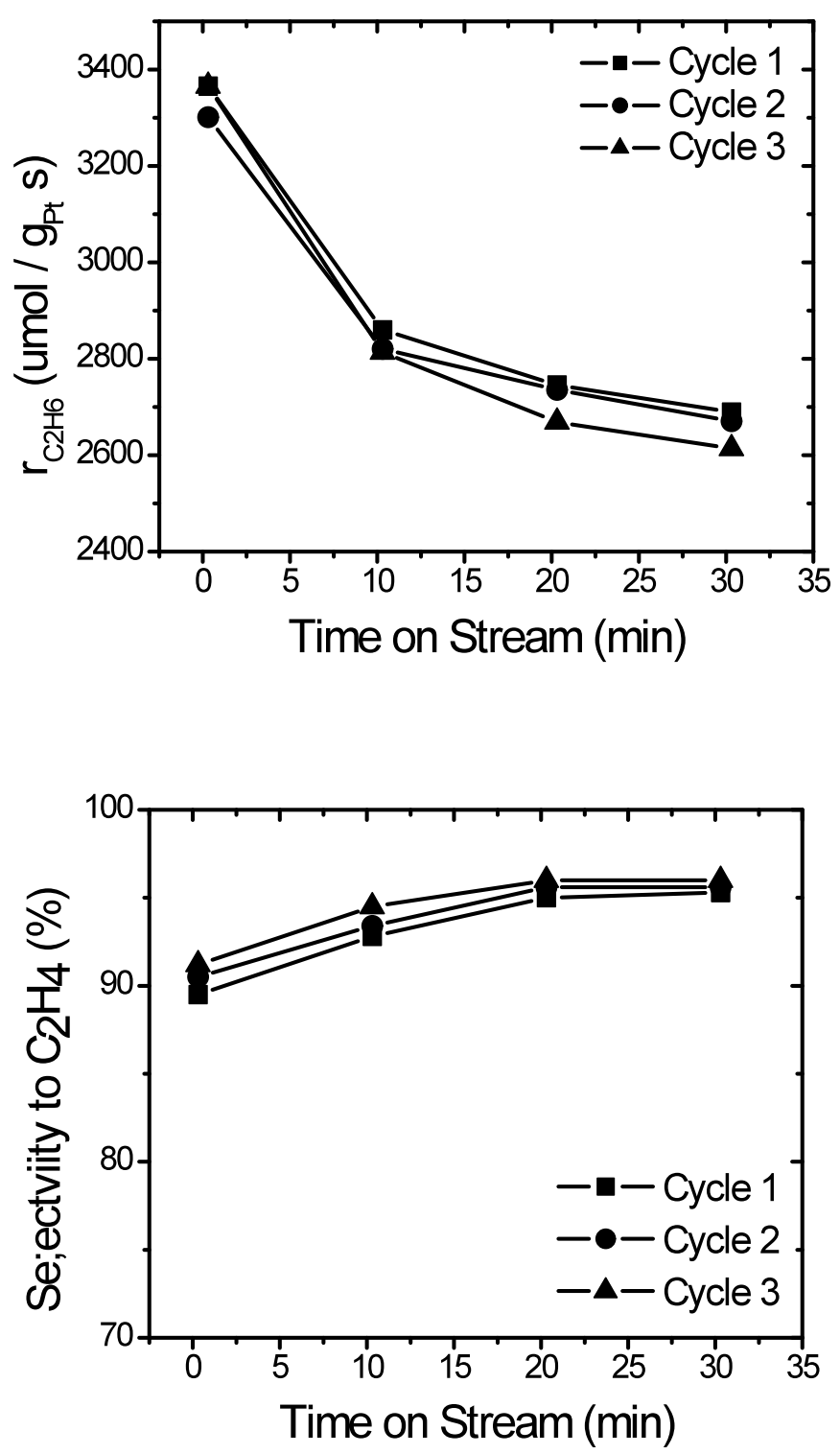

Fig. 10. Regeneration of $\mathrm{Pt}_{3} \operatorname{Ir} / \mathrm{Mg}(\mathrm{Al}) \mathrm{O}$ catalyst. In between each cycle, catalyst is treated at $873 \mathrm{~K}, 0.2$ bar $\mathrm{O}_{2}$, followed by $873 \mathrm{~K}, 0.2$ bar $\mathrm{H}_{2}$. 
(a)

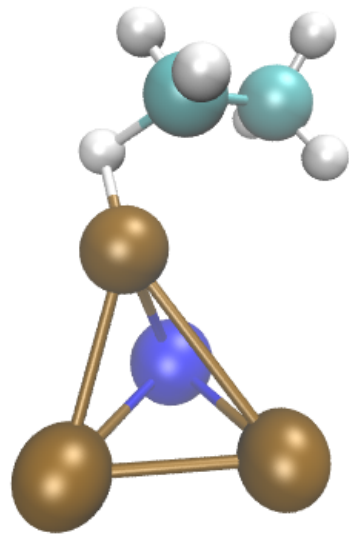

(b)

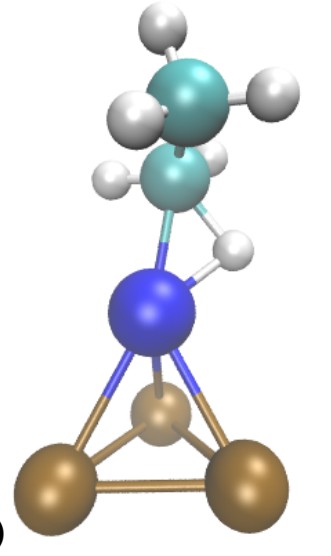

\begin{tabular}{c|c|c|c} 
Cluster & $\mathbf{X - C}$ & $\mathbf{X}-\mathbf{H}$ & $\mathbf{C}-\mathbf{H}$ \\
\hline $\mathrm{Pt}$ & 2.16 & 1.59 & 1.50 \\
$\mathrm{Pt}_{3} \mathrm{Ir}$ & 2.14 & 1.58 & 1.52 \\
$\mathrm{IrPt}_{3}$ & 2.12 & 1.62 & 1.47 \\
$\mathrm{Pt}_{3} \mathrm{Sn}$ & 2.16 & 1.59 & 1.49
\end{tabular}

Fig. 11. Transition state for dissociative adsorption of ethane on $\mathrm{Pt}_{3} \mathrm{Ir}$ cluster with active center as (a) Pt ( $\left.\mathrm{Pt}_{3} \mathrm{Ir}\right)$ and (b) $\mathrm{Ir}\left(\mathrm{IrPt}_{3}\right)$. The structure of the transition state and distances between the $\mathrm{C}, \mathrm{H}$ and active metal atoms are similar for all the metal clusters examined, as shown in the table (all distances in $\AA$ ).

\begin{tabular}{c|c|c|c} 
Cluster & $\boldsymbol{\Delta} \mathbf{H}_{\text {int }}$ & $\boldsymbol{\Delta} \mathbf{G}_{\text {int }}$ & $\mathbf{k}_{\mathbf{P t 3 X}} / \mathbf{k}_{\mathbf{P t} \mathbf{4}}$ \\
\hline $\mathrm{Pt}$ & 23 & 30 & 1 \\
$\mathrm{Pt}_{3} \mathrm{Ir}$ & 20 & 28 & 1.2 \\
$\mathrm{IrPt}_{3}$ & 11 & 15 & 14.9 \\
$\mathrm{Pt}_{3} \mathrm{Sn}$ & 20 & 17 & 9.2
\end{tabular}

Table 2. Intrinsic enthalpic and free energy activation barriers $(\mathrm{kJ} / \mathrm{mol})$ for the dissociative adsorption of ethane on 4-atom clusters. Ratio of reaction rate coefficients for each alloy with respect to pure Pt is shown in the last column. 


\section{Graphical Abstract}
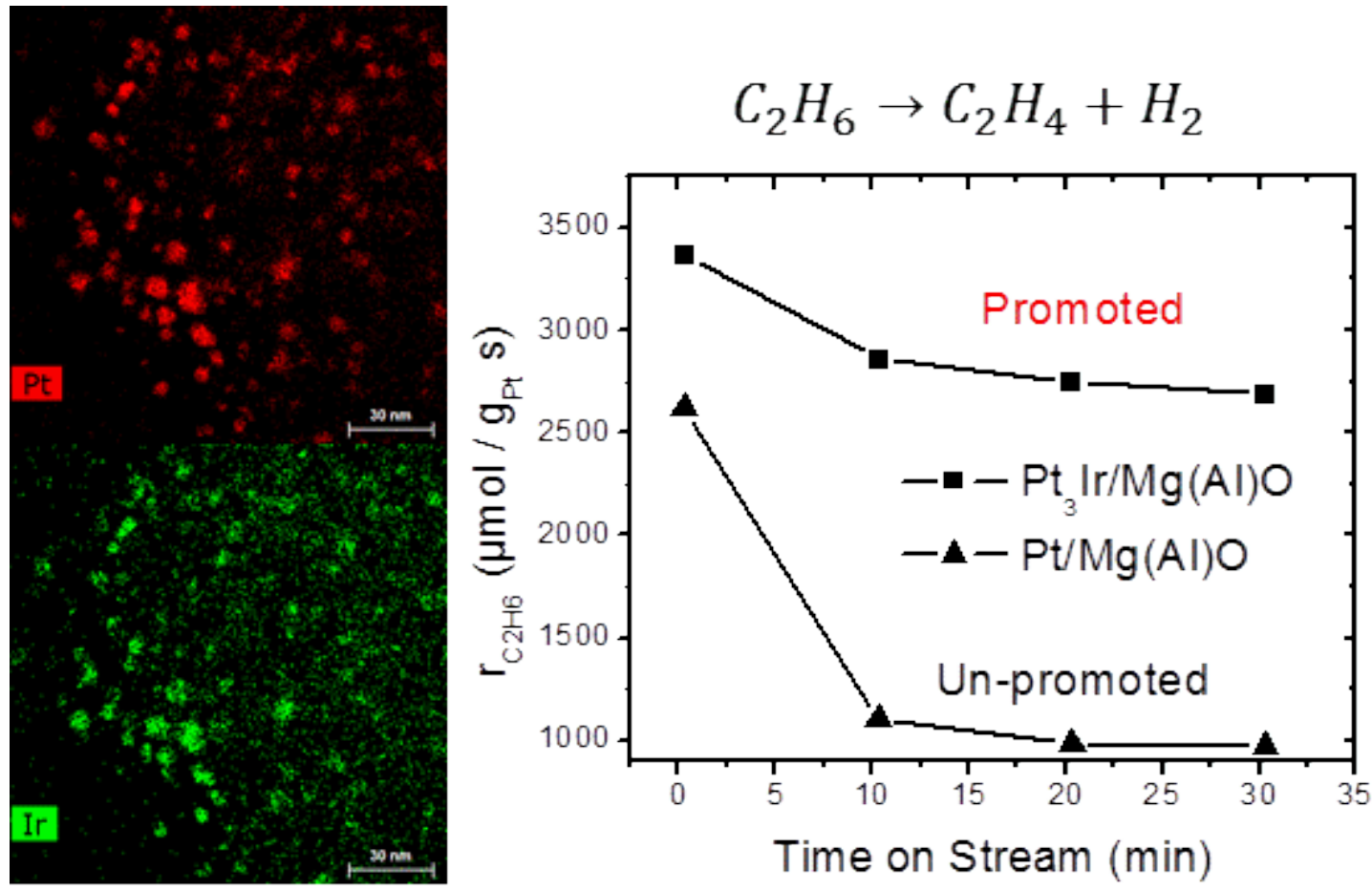